\title{
Adiponectin Level in Women with Breast Cancer
}

\author{
Fatemeh Homaee 1, Kamran Ghaffarzadehgan 2, Azar Aziminia ${ }^{3}$, Hamideh \\ Ghodrati $^{3}$, Azra Izanloo ${ }^{2}$, Reza Ziaolhagh ${ }^{2}$, Sahar Ardalan Khales ${ }^{4}$
}

${ }^{1}$ Faculty of Medicine, Mashhad University of Medical Sciences, Mashhad, Iran. ${ }^{2}$ Razavi Cancer Research Center, Razavi Hospital, Imam Reza International University, Mashhad, Iran. ${ }^{3}$ Veterinary Medicine, Ferdowsi University of Mashhad, Mashhad, Iran. ${ }^{4}$ Department of Modern and Sciences and Technologies, School of Medicine, Mashhad University of Medical Sciences, Mashhad, Iran.

\begin{abstract}
Introduction: Adiponectin is one of the plasma protein derived from adipose tissue which has a positive effect on the metabolism of fat and lipid, resulting from its own receptors. Increase in body mass index (BMI) has a direct relationship with life length. Obesity has effects on secretion of some hormones related to adipokines. Adiponectin is an adipokine having an opposite relationship with insulin resistance and breast cancer. There is also an association between breast cancer incidence and obesity. Adiponectin level decreases in women affected by breast cancer and knowing this fact can help treat and prevent the cancer by giving adiponectin supplements. The present study compared the adiponectin levels in women affected by breast cancer and healthy females as a control group. Material and Method: In this study, 80 women with breast cancer and 80 healthy females as controls were selected and adiponectin level was compared between them. Result: Breast cancer group had higher BMI mean $(28.77 \pm 6.05)$ and lower adiponectin level in comparison to control group $(\mathrm{p}=0.0001)$. Conclusion: Considering our findings, breast cancer risk is higher in women with higher BMI. Therefore, informing women in this regard could have a great effect on preventing this wide-spread disease. Taking adiponectin supplements as pills or injection could be a preventing step for breast cancer, which needs to be further cultivated in future studies.
\end{abstract}

Keywords: Adiponectin- breast cancer- BMI

Asian Pac J Cancer Biol, 2 (4), 91-94

\section{Introduction}

Breast cancer is one of the most common types of cancer in the world with 1.3 million affected people and causing 458000 death only in 2008 [1]. Breast cancer has become one of the most important causes of death among women, especially during menopausal age. It usually occurs due to genetic changes in somatic cells of the breast. However, it can also be caused by genetic heritage; genetic map could be a predisposing factor to the development of breast cancer.

In addition to mentioned factors, obesity has also attributed to prevalence of this disease [2]. Studies suggested that obesity is a risk factor for breast cancer after menopause; in addition, body mass index (BMI) increase can lead to breast cancer deterioration and life
Submission Date: 09/11/2017Ａcceptance Date: 11/25/2017

span decrease [3].

Growing trend of high-fat diet, which induces insulin resistance and subsequently obesity, is one of the greatest risk factors for diabetes and cardiovascular diseases. The molecular basis of this causal link has been discovered; adipose tissue, as the center of triglyceride and free fatty acids production, releases glycerol in response to the need for energy. As an important endocrine organ, it also produces some active biologic adipokines such as free fatty acid, adipsin, leptin, plasminogen, inhibitor activator, resistin, and TNF $\alpha$ [4]. Adiponectin is one of these adipokines received more attention recently.

Adiponectin is a protein with 244 amino acids, secreted from white adipose tissue and it has a crucial role in adjusting metabolism of fat and glucose [5]. It is also known as ACRP30 [3, 5-7]

\footnotetext{
Corresponding Author:

Dr. Kamran Ghaffarzadehgan

Razavi Cancer Research Center, Razavi Hospital, Imam Reza International University, Mashhad, Iran.

Email:kghafar46@gmail.com
} 
Adipose tissue, being crucial for growth and development of mammary gland, is one of the most important syntheses of lipid glands in animals [8]. One of the most significant factors, derived from lipid (adipokines), is adiponectin (ANP) [8]. Studies have shown that serum concentrations of adiponectin have an adversive effect on BMI and insulin resistance [8] Adiponectin gene, encoding 244 amino acids to produce adiponectin, is placed on chromosome $27 \mathrm{q} 3$, which is associated with metabolic syndrome and diabetes type 2 [5- 7]. This gene has two introns and three exons [7].

One of the adipokines that plays an important role in the directive relationship between breast cancer and obesity is adiponectin. It is the most crucial adipocytokine in the bloodstream. While other cytokines like leptin cause obesity and heart disease, adiponectin decreases obesity [9-10]. This effect may be for this reason that although by producing adipose tissue the level of adiponectin increases, but has a restraining feedback on its own production [10]

Increase in weight and adipose tissue among adults has a direct relationship with breast cancer in menopausal women and inverse effect in pre-menopausal females [11-12]. Researchers have shown that lower levels of total adiponectin or HMW are correlated with the increased risk of breast cancer in menopausal women [13-14].

The present study compared women affected by breast cancer with healthy females in terms of adiponectin levels. Since the current investigation was performed for the first time in Iran, the findings would be helpful in this field.

\section{Materials and Methods}

In this study, case-control method was used. Data were analyzed by SPSS. The correlation coefficient was considered $95 \%$ and power of correlation test $80 \%$. Using data derived from another study [15], the concluded sample size was 40 cases for cancer group and 40 for the control group.

Eighty women who were newly diagnosed with breast cancer and received no treatment yet were chosen from patients of a cancer hospital as case group. For the control group, 80 healthy women, who were among referents in a private laboratory, were selected.

Age, height, and weight of females in both groups were recorded and the BMI of each participant was calculated accordingly. The age range of participants was 30 to 70 and females lower and above this age range were eliminated from the study. Written informed consent was obtained from all the participants. The data of the ones who didn't show an inclination to take part in the study were omitted. Eventually, 40 females were selected for case group according to our defined criteria.

For the control group, 40 women were also selected. The data were gathered in 3 months and then were analyzed .In this study, the Elisa method was applied for data analysis.

\section{Statistical analysis}

The gathered data were coded and then analyzed by SPSS. To test the validity of the assumptions of the study, the independent T-test and Pearson correlation were applied.

\section{Results}

Distribution Analysis of participants'age

On average, the mean age of participants in the control group was 50/68 $\pm 11 / 31$ and it was $46.45 \pm 9.37$ in the case group. Since the age of women as the intervening variable can affect the level of adiponectin and other variables of the study, two groups were compared in terms of age . According to the results of T-student or independent T-test, there was a significant difference between two groups $(\mathrm{p}=0.011)$.

\section{Distribution Analysis of participants' BMI}

BMI mean was $26.04 \pm 4.5$ for the control group and $28.77 \pm 6.05$ for the case group. Since the BMI of females as an intervening variable can affect the variables of the study, it was compared between two groups. The results of T-test showed a significant difference between two groups $(p=0.06)$.

\section{Frequency distribution of adiponectin in control and case group}

Diagram 1 shows frequency distribution of adiponectin in control group and diagram 2 depicts that in the case group. As can be seen, the mean frequency of adiponectin in the control group was $11.48 \pm 4.05$ and $8.63 \pm 2.85$ in the case group. The result of T-test showed a significant difference between two groups in terms of adiponectin frequency $(p=0.0001)$.

The correlation between adiponectin level and weight, height, BMI, and age was determined by Pearson correlation test and the results are shown in Table 1.

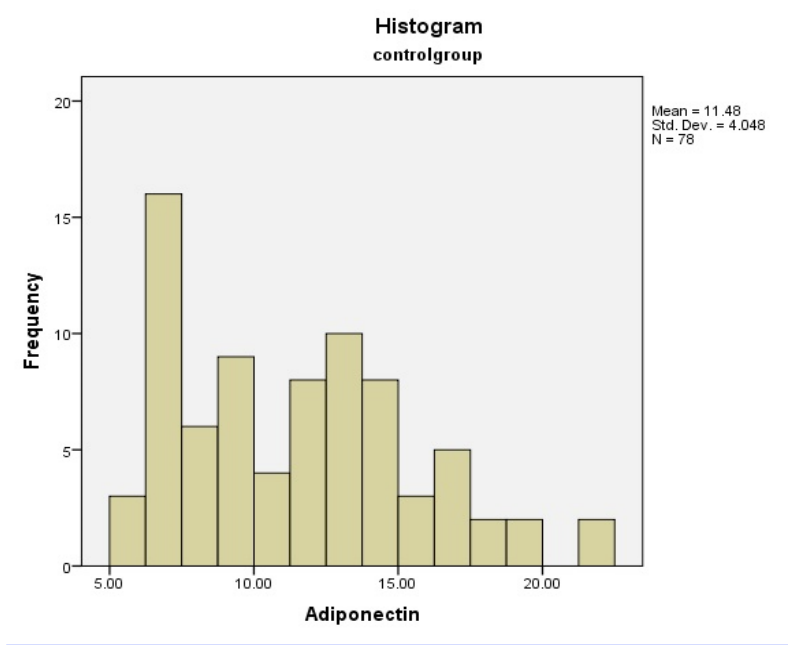

Figure 1. Frequency Distribution of Adiponectin in Control Group 


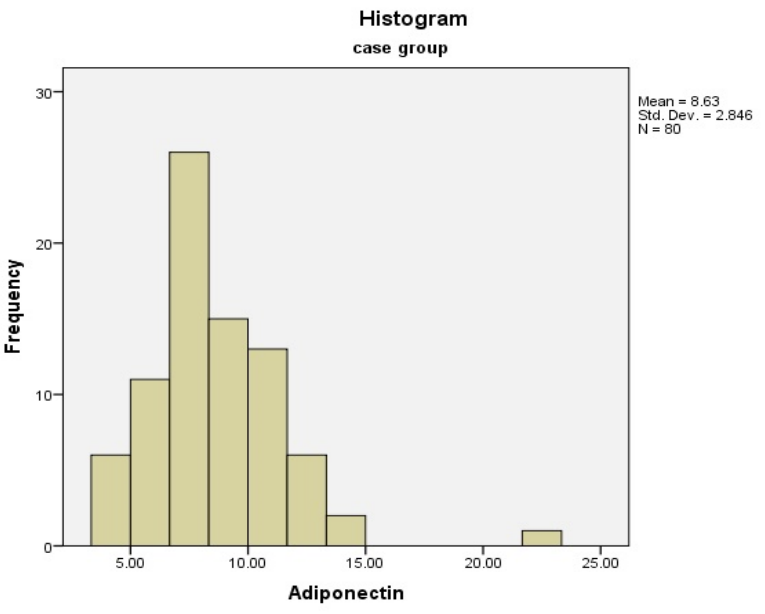

Figure 2. Frequency Distribution of Adiponectin in Case Group

Table 1. Pearson correlation test between adiponectin level and age, height, weight, and BMI of the participants

\begin{tabular}{lccc}
\hline Group & Variable & P-Value & $\mathrm{R}$ \\
\hline \multirow{4}{*}{ Control } & Age & 0.582 & -0.063 \\
& Height & 0.007 & 0.30 \\
& Weight & 0.01 & -0.28 \\
& BMI & 0.0001 & -0.43 \\
Case & Age & 0.67 & -0.048 \\
& Height & 0.03 & 0.24 \\
& Weight & 0.01 & -0.029 \\
& BMI & 0.06 & -0.30 \\
\hline
\end{tabular}

\section{Discussion}

With respect to the results of the present study, there was a significant difference between the age of the cancer group and that of the control group. This variable showed a bigger mean value in control group, indicating no dependency between developing breast cancer and adiponectin level. These results are in contrast to the findings of a study conducted by Mantozoros et al. in 2004. The aforementioned study compared decreased adiponectin level in menopausal and pre-menopausal women affected by breast cancer and a large decrease in pre-menopausal women was reported [6].

Considering BMI, as an independent variable, BMI mean was higher for cancer group in comparison to control group, revealing that the BMI in women with breast cancer is higher than healthy women. It seems that BMI has an inverse relationship with adiponectin level, proving the assumptions of the study. This finding agrees with a study by Shelly S. Tworoger et al. conducted in 2013. They concluded that women after menopause, who have a larger BMI, tend to develop cancer more than the ones with lower BMI [16] Concerning adiponectin, in agreement with other studies [1, 5, 17, 18], the present study showed that adiponectin had a lower range in women with breast cancer and higher BMI in comparison with control group. Aditionally, our findings are in line with those revealed by a meta-analysis done in 2013, investigating 13 studies conducted from 2003 to 2013 and examining the relationship between adiponectin level and breast cancer incidence. The results showed an inverse connection between these two variables [13]

In conclusion, the purpose of this study was to identify the correlation between adiponectin level and breast cancer incidence. Discovering an inverse relationship between these two, we can anticipate the risk of cancer in women by measuring adiponectin level. Considering our findings, breast cancer risk is higher in women with higher BMI. Therefore, informing women in this regard could have a great effect on preventing this wide-spread disease. Taking adiponectin supplements as pills or injection could be a preventing step for breast cancer, which needs to be further cultivated in future studies.

\section{Conflict of Interest}

The authors declared no conflict of interest.

\section{References}

1. Liu LY, Wang M, Ma ZB, Yu LX, Zhang Q, Gao DZ, et al. The role of adiponectin in breast cancer: a meta-analysis. PLoS One. 2013;8(8):e73183.

2. Hall JM, Lee MK, Newman B, Morrow JE, Anderson LA, Huey B, et al. Linkage of early-onset familial breast cancer to chromosome 17q21. Science. 1990;250(4988):1684-9.

3. Grossmann ME, Nkhata KJ, Mizuno NK, Ray A, Cleary MP. Effects of adiponectin on breast cancer cell growth and signaling. British journal of cancer. 2008;98(2):370-9.

4. Kadowaki T, Yamauchi T. Adiponectin, and adiponectin receptors. Endocrine reviews. 2005;26(3):439-51.

5. Dalamaga M, Diakopoulos KN, Mantzoros CS. The role of adiponectin in cancer: a review of current evidence. Endocrine reviews. 2012;33(4):547-94.

6. Mantzoros C, Petridou E, Dessypris N, Chavelas C, Dalamaga $\mathrm{M}$, Alexe DM, et al. Adiponectin and breast cancer risk. The Journal of clinical endocrinology and metabolism. 2004;89(3):1102-7.

7. Takahashi M, Arita Y, Yamagata K, Matsukawa Y, Okutomi K, Horie $\mathrm{M}$, et al. Genomic structure and mutations in adiposespecific gene, adiponectin. International journal of obesity and related metabolic disorders: journal of the International Association for the Study of Obesity. 2000;24(7):861-8.

8. Landskroner-Eiger S QB, Muise ES, Nawrocki AR, Berger JP, Fine EJ, et al. Proangiogenic contribution of adiponectin toward mammary tumor growth in vivo. Clinical Cancer Research. (2009).

9. Vayghan HJ, Esfanjani A.T, Ebrahimi Mameghani1 M, Asghari Jafarabadi M, Ghadimi S, Lalezadeh Z. Sex Differences in Serum Leptin and Adiponectin levels in Apparently Healthy Iranian Adults. International Research Journal of Applied and Basic Sciences,. (2013). ;4,:3099-103.

10. Chandran M, Phillips SA, Ciaraldi T, Henry RR. Adiponectin: more than just another fat cell hormone? Diabetes care. 2003;26(8):2442-50

11. Carmichael AR, Bates T. Obesity and breast cancer: a review of the literature. Breast (Edinburgh, Scotland). 2004;13(2):85-92.

12. Vrieling A, Buck K, Kaaks R, Chang-Claude J. Adult weight gain in relation to breast cancer risk by estrogen and progesterone receptor status: a meta-analysis. Breast cancer research and treatment. 2010;123(3):641-9.

13. Trujillo ME, Scherer PE. Adiponectin a journey from an adipocyte secretory protein to biomarker of the metabolic 
syndrome. Journal of internal medicine. 2005;257(2):167-75.

14. Ouchi N, Kobayashi H, Kihara S, Kumada M, Sato K, Inoue $\mathrm{T}$, et al. Adiponectin stimulates angiogenesis by promoting cross-talk between AMP-activated protein kinase and Akt signaling in endothelial cells. The Journal of biological chemistry. 2004;279(2):1304-9.

15. Macis D, Guerrieri-Gonzaga A, Gandini S. Circulating adiponectin and breast cancer risk: a systematic review and meta-analysis. International journal of epidemiology. 2014;43(4):1226-36.

16. Chen DC, Chung YF, Yeh YT, Chaung HC, Kuo FC, Fu OY, et al. Serum adiponectin and leptin levels in Taiwanese breast cancer patients. Cancer letters. 2006;237(1):109-14.

17. Kang JH, Yu BY, Youn DS. Relationship of serum adiponectin and resistin levels with breast cancer risk. Journal of Korean medical science. 2007;22(1):117-21.

18. Arditi JD, Venihaki M, Karalis KP, Chrousos GP. Antiproliferative effect of adiponectin on MCF7 breast cancer cells: a potential hormonal link between obesity

\section{(ब) $\odot$}

This work is licensed under a Creative Commons AttributionNon Commercial 4.0 International License. 